\title{
Mathematical Modeling of Arc Faults in Networks with Low Single Phase-to-Ground Fault Currents
}

\author{
Andrei Brilinskii ${ }^{1}$, Georgiy Evdokunin ${ }^{2}$, Anna Petrova ${ }^{2,3 *}$, and Irina Ryndina ${ }^{2}$ \\ ${ }^{1}$ Electrical Power Systems Design and Development Department, JSC “Scientific and Technical Center of Unified Power System”, 1 \\ lit A Kurchatov Str., St. Petersburg, 194223, Russia \\ ${ }^{2}$ Higher school of Electric Power Systems, Institute of Energy, Peter the Great St. Petersburg Polytechnic University, 29 \\ Polytechnicheskaya Str., St. Petersburg, 195251, Russia \\ ${ }^{3}$ Scuola di Ingegneria Industriale e dell'Informazione - MI, Politecnico di Milano, Piazza Leonardo da Vinci 32, 20133 Milano, Italy
}

\begin{abstract}
The article comprises the results of the research defining open-flame arcs self-quenching conditions in the event of a single phase-to-ground fault in overhead medium-voltage distribution networks according to existing theories of arc extinguishing. The calculations included metallic and arc faults modeling in a network with low phase-to-ground fault current. The arc gap simulation based on the mathematical channel model of a cylindrically symmetrical upright arc stabilized by rising convective gas flow was carried out in ATPDraw software program. The single phase-to-ground arc fault calculations results indicated an increase in high-frequency currents' attenuation rate during transient processes as well as a reduce reduction in the electric arc lifetime from $8 \mathrm{~ms}$ to $2 \mathrm{~ms}$ in case of the breakdown voltage decrease from the peak value to zero. Notably, in case of low single phase-to-ground fault current the arc extinguishing took place at the first high-frequency current zero. For the cases of nonzero breakdown voltages, the electric arc extinguishing was detected at the fundamental frequency current component zerocrossing instant. The maximum overvoltage ratio of $\mathrm{K}=2.8$ was obtained as athe result of the single phase-to-ground fault at the peak phase voltage.
\end{abstract}

\section{Introduction}

The chief advantage of insulated neutral distribution systems lies in the network line voltage continuity in case of a single metallic phase-to-ground fault, therefore steady supply of the customers can be carried out in practice [1]. During nonmetallic ground faults, namely electric arc faults, various arcing modes can take place that directly depend not only on the fault current, but also the arc plasma gap deionization conditions. A stable arc existence is possible if the fault current is high as long as the gap is not able to deionize significantly during the current zero-crossing. At low currents the arc extinction tends to occur during first current zerocrossings. Therefore, in the absence of necessity to isolate the damaged network section it is sufficient to diminish its negative influence on the rest of the working network, particularly mitigate the possibility of the arc development or decrease the ground-fault current in case of stable arcing.

Reliable and safe network operation requires such a ground-fault current value that fault development possibility remains neglectable continuously. In compliance with [2] for $6,10,35 \mathrm{kV}$ electric power networks in Russian Federation the upper-range values of phase-to-ground fault current are 30, 20, $10 \mathrm{~A}$ respectively. Furthermore, the rated ground-fault current values are slated to provide arc self-quenching or promote successful reclosing of the faulted line if available.

Significantly, the rated current values are accepted without due justification of self-quenching efficiency. In addition, any works illustrating real time of open-flame arcs existence before self-quenching are nowhere in evidence.

Over the course of many decades there have been three generally accepted theories dedicated to fault arcs in overhead networks extinguishing conditions and corresponding overvoltage development mechanisms: the Petersen theory [3] stating that the arc goes out during the first high-frequency current zero-crossing, that means the arcing process lasts for half-period of free oscillations; the Peters-Slepyan theory [4], whereby the arc extinguishes at the instant of fundamental current component zero-crossing; the Belyakov theory [5] claiming that the arc is able to go out in both cases.

Thereby the analysis of the processes tracking arcs extinguishing during single phase-to-ground faults with the computer model implementation will allow to detect the event of self-quenching, verify and probably update

\footnotetext{
* Corresponding author: petrova4anna@gmail.com
} 
universal assumptions as well as assess lifetime of ground-fault arcs.

\section{Methods}

\subsection{Network structure}

For electric arc behavior investigation represented by the mathematical model implemented in a neutral-insulated network a real part of $35 \mathrm{kV}$ network of the electric power system of Saint-Petersburg and Leningrad region was taken. The network structure is illustrated in Figure 1.

The $35 \mathrm{kV}$ section was described in ATPDraw software program as a set of $110 / 35 / 10$ and $35 / 10 \mathrm{kV}$ step-down transformers and $35 \mathrm{kV}$ overhead lines, $10 \mathrm{kV}$ load was not taken into account.

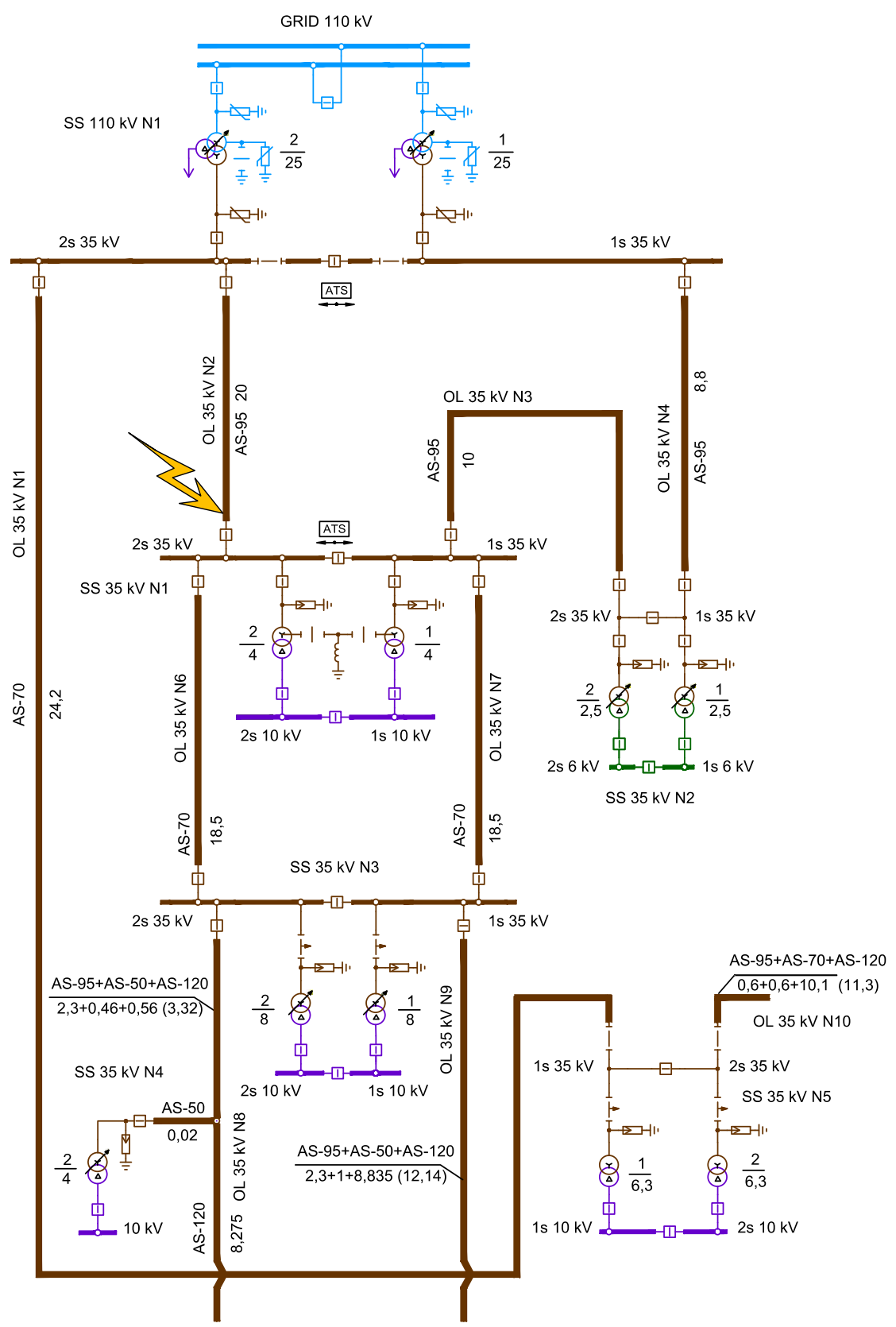

Fig. 1. The $35 \mathrm{kV}$ network structure.

\subsection{Mathematical open-flame arc model}

To carry out the ground-fault transients analysis using ATPDraw software program $[6,7]$ the mathematical open-flame arc model with the algorithm described in [8-
10] was implemented. Unlike in other models [11-19], in this paper the channel model of a cylindrically symmetrical upright arc stabilized by rising convective gas flow was accounted for the simulation. The arc channel was defined as cylindrically symmetrical, electrode sheaths were ignored. Plasma was supposed to be quasi-isothermal and quasi-neutral. Pressure was 
considered to be constant and equal to the atmosphere one. Magnetic effects, viscosity, radial convective gas flows and emission were neglected due to insignificance. After all the assumptions implementation the mathematical formulation of the burning arc processes was reduced to a dynamic second-order partial temperature dependent energy equation. The criterion of the arc extinguishment which equation was solved simultaneously with the external network transient equations was the loss of the whole arc column conductivity. Once the arc elongation due to rising convective gas flows entails increase in the arc resistance and provokes self-quenching at lower currents as a consequence, the most severe case study outlined as the arc elongation ignorance was under consideration.

It was safe enough to assume the arc length equal to the average factory length of $35 \mathrm{kV}$ insulator that corresponded to $300 \mathrm{~mm}$.

\section{Results and Discussion}

A metallic single phase-to-ground fault at the instant of peak phase voltage $t_{1}=40 \mathrm{~ms}$ was under consideration first. The neutral-to-ground voltage and the fault current curves are shown in Figure 2.

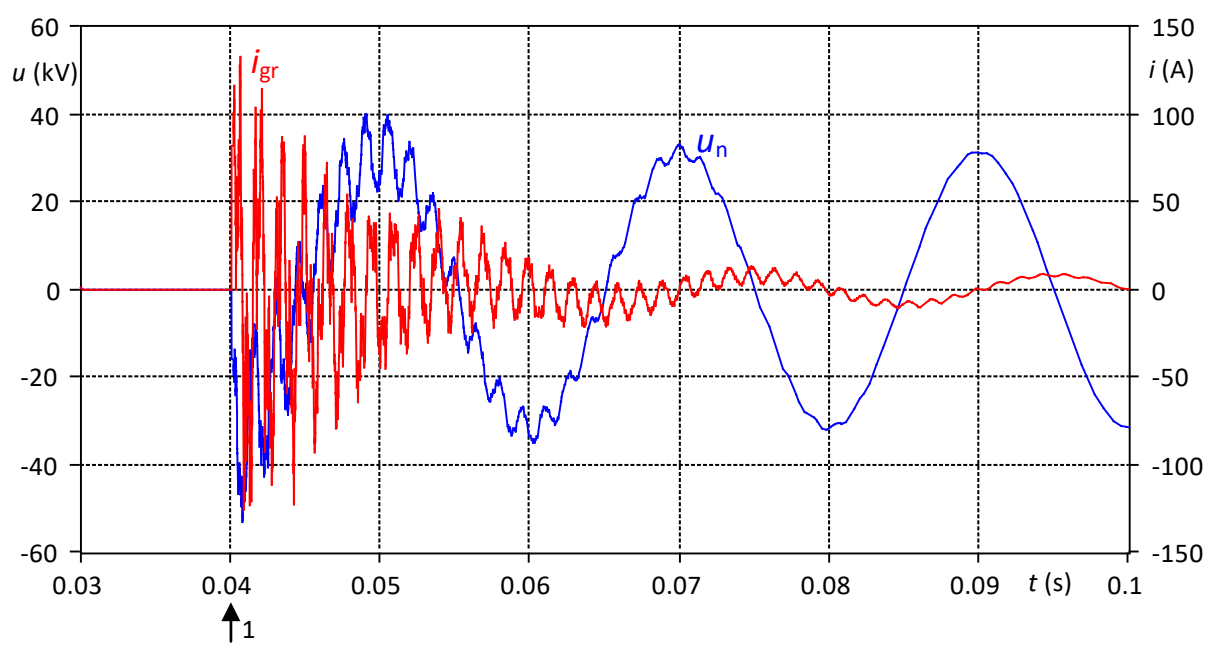

Fig. 2. The fault current and the neutral-to-ground voltage oscillograms, metallic ground fault $\mathrm{t}_{1}=40 \mathrm{~ms}$ (peak phase voltage).

The effective value of the steady-state ground-fault current in the network concerned was equal to $\mathrm{I}_{\mathrm{gr}}=6 \mathrm{~A}$. The peak current value at the initial instant reached $\mathrm{I}_{\mathrm{gr}}$ $\max =140 \mathrm{~A}$. The neutral-to-ground voltage after the transient attenuation levelled off and settled at the phase voltage value (Figure 3) [20].
At the initial instant after the single phase-to-ground fault occurred the voltages to ground of the healthy phases rose, the overvoltage rate approached to the value of $\mathrm{K}=2.74$

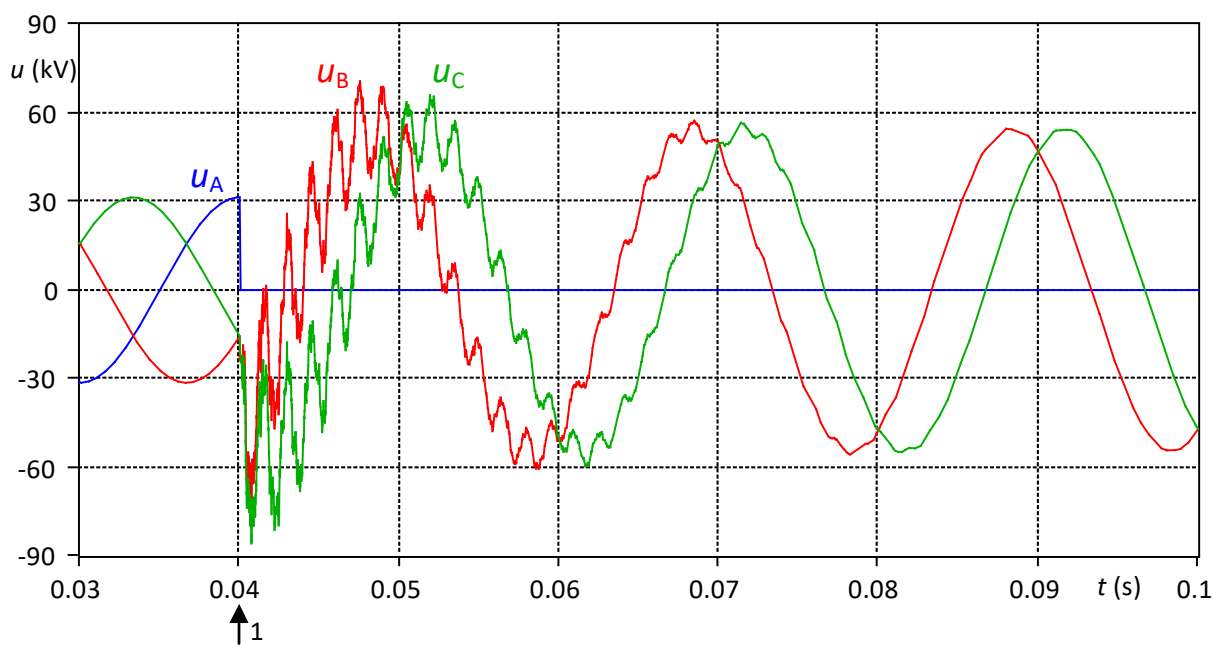

Fig. 3. The phase voltage oscillograms, metallic ground fault $\mathrm{t}_{1}=40 \mathrm{~ms}$ (peak phase voltage). 
Single phase-to-ground faults can arise potentially at any instantaneous value of the phase voltage of the network including zero. Variation of the high-frequency fault current component amplitude (at a constant magnitude of the fundamental frequency fault current component $50 \mathrm{~Hz}$ ) that altered according to the moment of the ground fault initiation was aimed at assessment of the first arc extinction theory conceived by Petersen. If the breakdown voltage ranged from its maximum (Figure 2, 3) to zero value (Figure 4,5 ) the peaks of the high-frequency ground-fault current dropped from $140 \mathrm{~A}$ to the level of $15 \mathrm{~A}$ coupled with arc overvoltage rates (from $\mathrm{K}=2.7$ to $\mathrm{K}=1.74$ ).

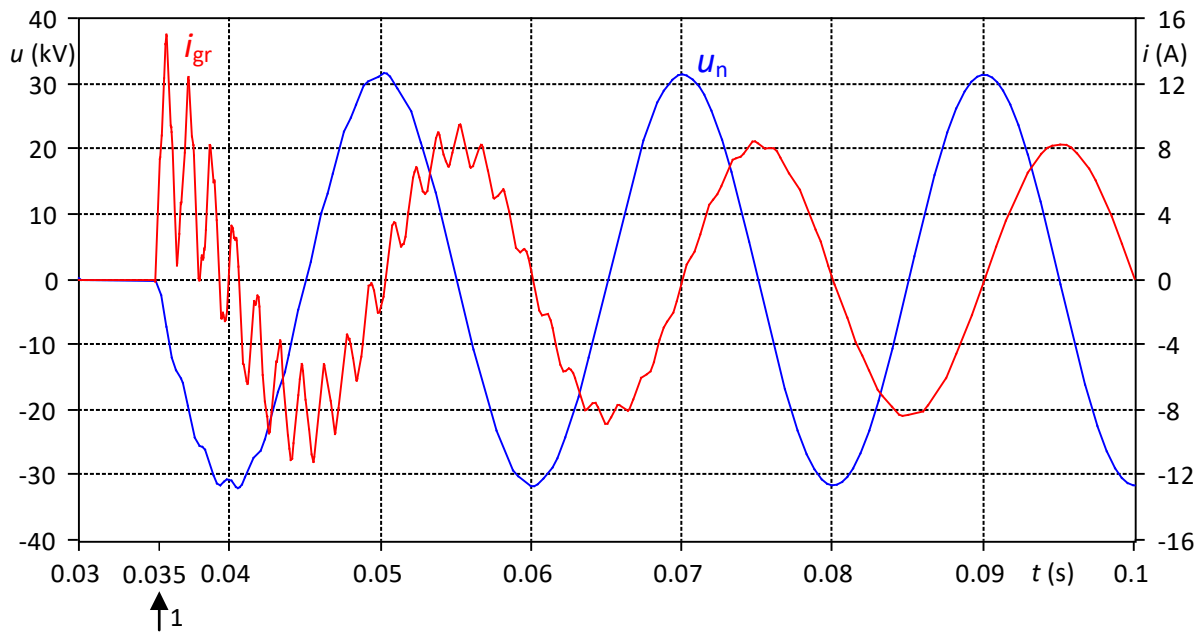

Fig. 4. The fault current and the neutral-to-ground voltage oscillograms, metallic ground fault $\mathrm{t}_{1}=35 \mathrm{~ms}$ (zero phase voltage).

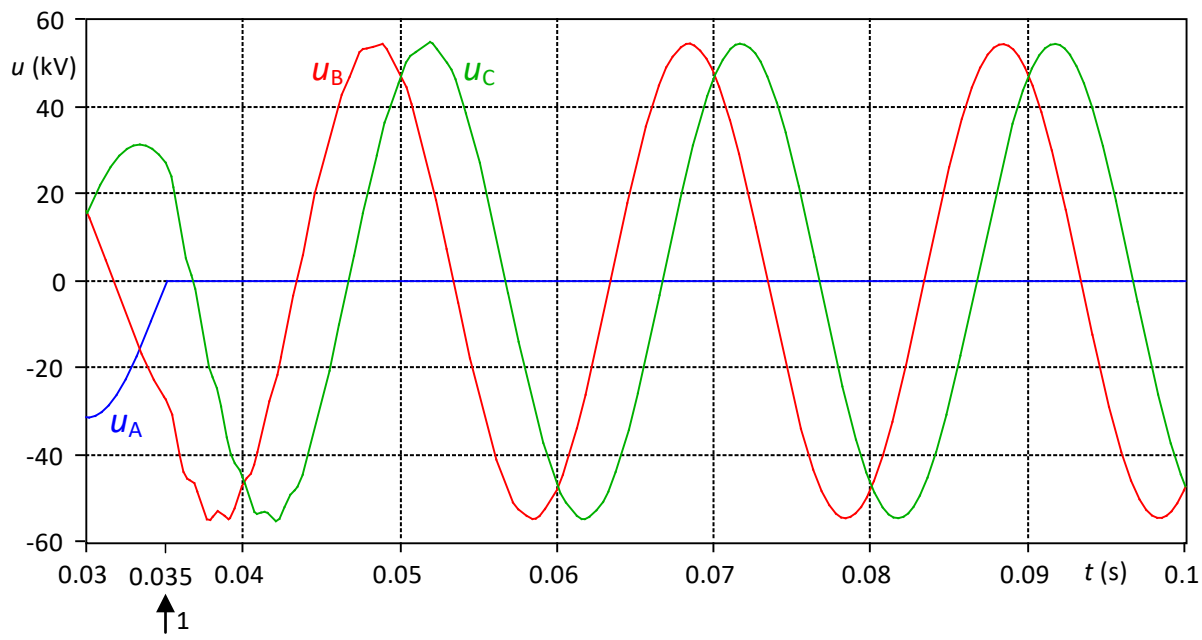

Fig. 5. The phase voltage oscillograms, metallic ground fault $\mathrm{t}_{1}=35 \mathrm{~ms}$ (zero phase voltage).

In most cases to simplify the calculations metallic single phase-to-ground faults are under consideration. Nonetheless, typically there is a transient resistance at the fault location, usually arc resistance [21]. The calculations similar to the described earlier (Figures 2-5) and adjusted for the mathematical arc model implementation were conducted (Figures 6-7). Thus, an open-flame arc arising out of a flashover in the $35 \mathrm{kV}$ network was put under consideration. 


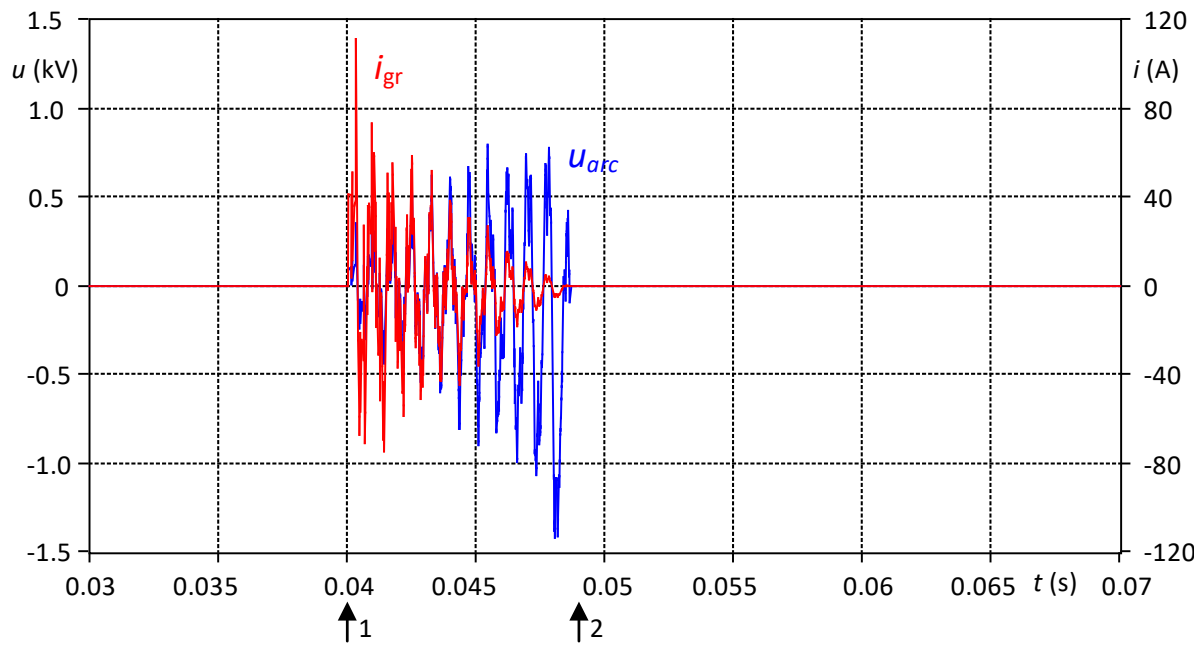

Fig. 6. The fault current and the arc voltage oscillograms, arcing ground fault $\mathrm{t}_{1}=40 \mathrm{~ms}$ (peak phase voltage).

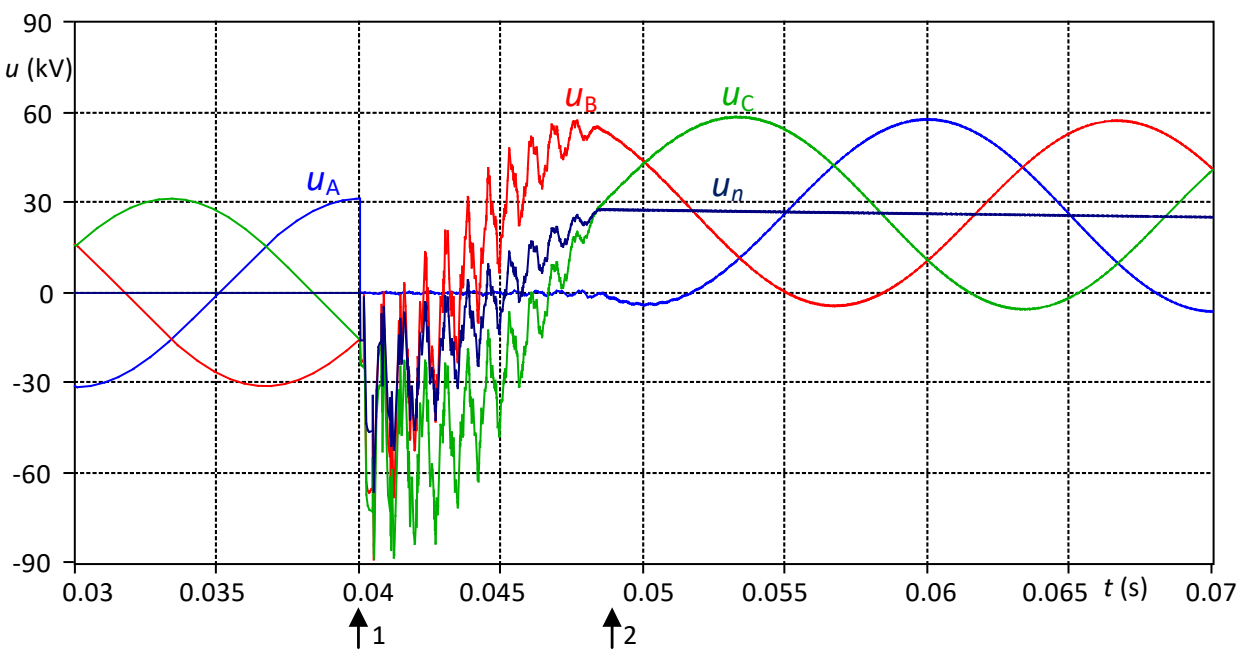

Fig. 7. The phase-to-ground voltage and the neutral-to-ground voltage oscillograms, arcing ground fault $\mathrm{t}_{1}=40 \mathrm{~ms}$ (peak phase voltage).

The Figures 6, 7 show that owing to a significant voltage drop at the electric arc the arc current tended to descend entailing the arc extinction, so the arc selfquenching seized the time interval of $\Delta \mathrm{t}=8 \mathrm{~ms}$. That indicated that the arcing process was unstable and approximately half-period of industrial frequency after the arc initiation it went out, that coincided with the Petersen theory.

As soon as the arc self-quenching took place the phase-to-ground voltages at the ground fault location turned out to be shifted due to the neutral-to-ground voltage displacement equal to practically the phase-toground voltage value of the network under consideration [22]. The overvoltage ratio at the initial instant reached the level of $\mathrm{K}=2.8$.

Putting Figure 6 and Figure 2 in comparison it can be noticed that the peak value of the high-frequency current component reached the lower value of $\mathrm{I}_{\mathrm{gr} \max }=110 \mathrm{~A}$ and also attenuated faster in case of the arcing ground fault. It was bound with active losses at the electric arc element that rendered increase in the damping rate of the high-frequency component. The overvoltage ratio coupled with the peak value of the single phase-toground current did not change.

Furthermore, a certain study series involving variation of the ground fault instant at $1 \mathrm{~ms}$ intervals was conducted. The ground fault current value decreased as the fault instant stepped from the peak value of the faulted phase voltage to zero. Notwithstanding the fact of downtrend in the high-frequency current component amplitude, the electric arc continued extinguishing at the moment of the fundamental current component zerocrossing. Figures 8, 9 represent the curves under consideration when the single phase-to-ground fault took place near the zero phase voltage. 


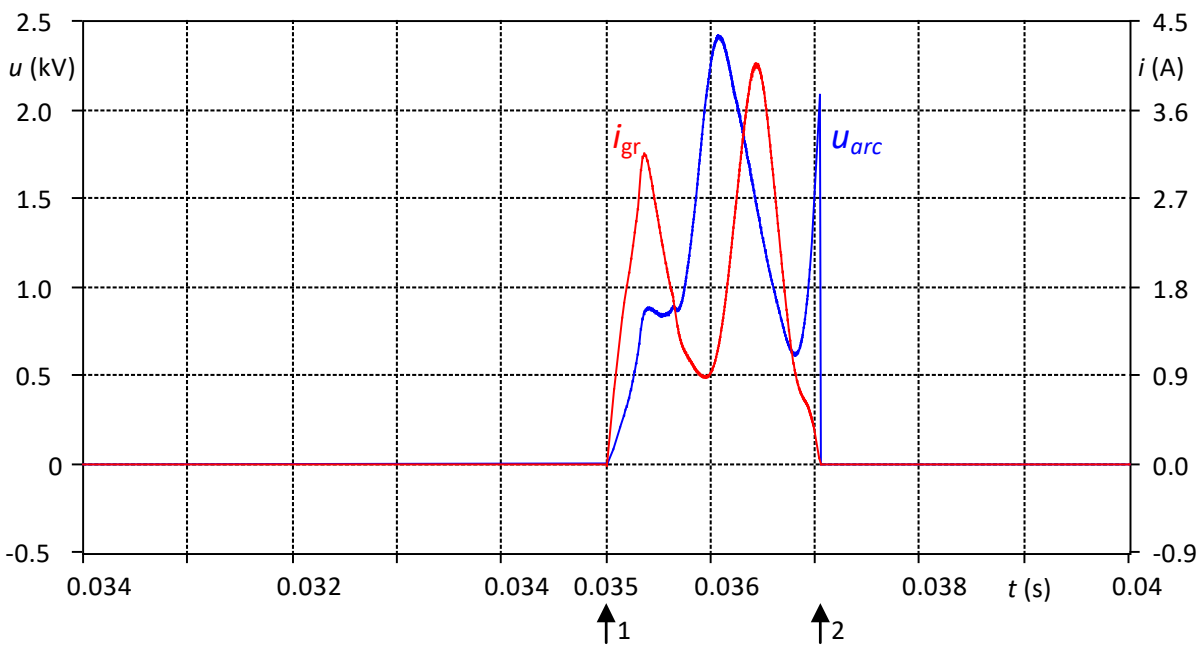

Fig. 8. The fault current and the arc voltage oscillograms, arcing ground fault $\mathrm{t}_{1}=35 \mathrm{~ms}$ (zero phase voltage).

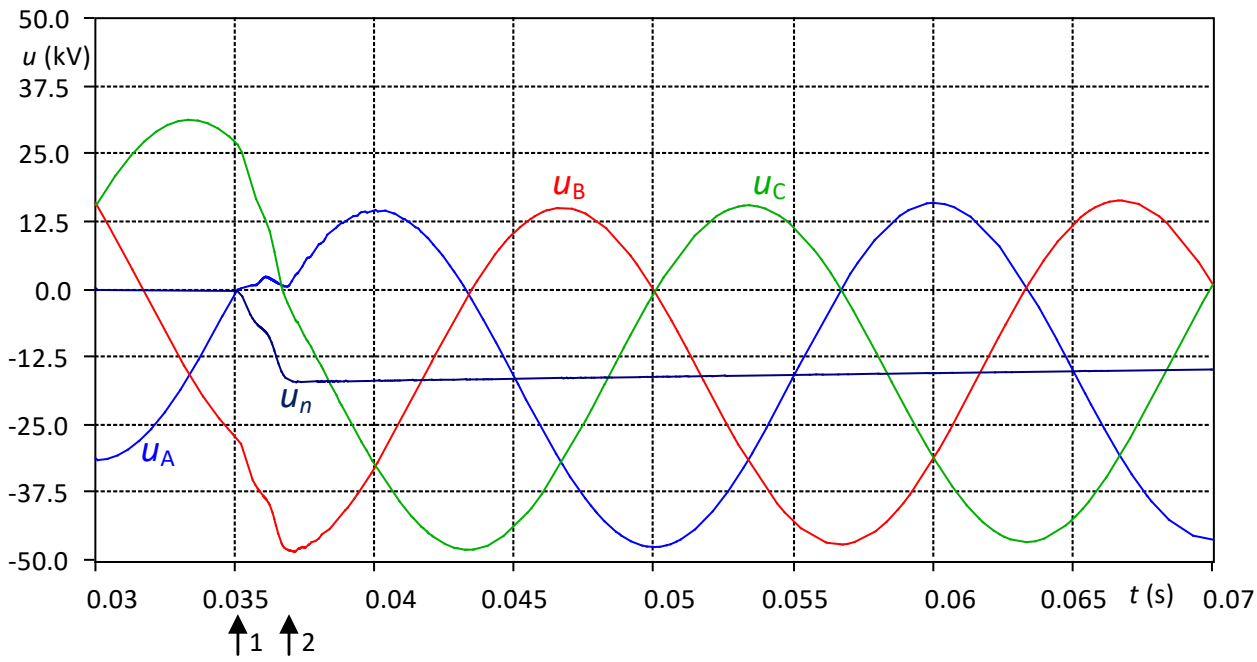

Fig. 9. The phase-to-ground voltage and the neutral-to-ground voltage oscillograms, arcing ground fault $\mathrm{t}_{1}=35 \mathrm{~ms}$ (zero phase voltage).

In contrast to the case of the metallic single phase-toground fault at the zero phase voltage instant (Figure 4, 5) the peak value of the first current oscillation reached $\mathrm{I}_{\text {gr max }}=4 \mathrm{~A}$. According to the calculations, the current comprised the high-frequency component with such an amplitude that during first several high-frequency periods ( $f=500 \mathrm{~Hz}$ ) the ground fault current did not cross zero. Further the arc voltage drop leaded to the arc extinction. The less was the ground fault current the larger was the arc gap resistance, therefore the voltage drop increased. At the time instant $\mathrm{t}_{2} \approx 37 \mathrm{~ms}$ the arc resistance became so significant that the arc extinguished during the first zero-crossing. The arc duration was $\Delta \mathrm{t}=$ $2 \mathrm{~ms}$. The marginal case represented the minimal highfrequency component value that could exist, under the provided circumstances the arc self-quenching occurred according to the Petersen theory. Notably, during the transient the healthy phases did not experience highfrequency overvoltages (Figure 9).

The following Table 1 comprises all the crucial numerical values obtained as the results of the calculations.
Table 1. The calculations results.

\begin{tabular}{|c|c|c|c|}
\hline Igr, A & $\boldsymbol{U}_{\mathbf{A}} / \boldsymbol{U}_{\mathbf{A} \max }$ & $\Delta \boldsymbol{t}, \mathbf{~} \mathbf{s}$ & $\mathbf{K}$ \\
\hline \multirow{4}{*}{6} & 1 & 8 & 2.9 \\
\cline { 2 - 4 } & 0.95 & 7 & 2.7 \\
\cline { 2 - 4 } & 0.81 & 7 & 2.5 \\
\cline { 2 - 4 } & 0.59 & 6 & 2.2 \\
\cline { 2 - 4 } & 0.31 & 4 & 1.95 \\
\cline { 2 - 4 } & 0 & 2 & 1.6 \\
\hline
\end{tabular}

\section{Conclusions}

Taking the arcing process in consideration the single phase-to-ground fault calculations showed significant increase in the speed of the high-frequency current component attenuation. The ground fault time before the arc self-quenching was from $20 \mathrm{~ms}$ to $5 \mathrm{~ms}$ depending of the initiation moment. Obviously, the arc existed for a longer time period if the ground fault occurred near the peak phase-to-ground voltage value, so not only the high-frequency component was larger, but also the attenuation process was more time-consuming.

The Petersen theory was proven to be practically relevant only for low high-frequency current components 
when the fault took place at zero phase voltage (low probability of the event). The prevailing part of the cases indicated the arc self-quenching during the fundamental current component zero-crossing, so the arc extinguishing conformed the Peters-Slepyan theory stating the arc extinction in a half-period of $50 \mathrm{~Hz}$ oscillation interval after its initiation with the decay of the free oscillations, namely during the first fundamental current component zero-crossing.

The results obtained can be particularly helpful for the authors [23-27].

\section{References}

1. G. A. Evdokunin and S. S. Titenkov, Resistive Neutral Grounding of $6-10 \mathrm{kV}$ Networks (Tertsia, St.Petersburg, 2009)

2. Rules for Arrangement of Electrical Installations, $6^{\text {th }}-7^{\text {th }}$ ed. (Normatika, 2019), pp. 8-9

3. W. Petersen, Elektrotechn. Z. Bd., 341 (1919)

4. J. F. Peters and J. Slepyan, IEEE Trans. Power Syst, 478 (1923)

5. N.N. Belyakov, Elektrichestvo, 46 (1958)

6. A. Rifaldi and R. B. Lastra, Electronic Edition of ATP Rulebook in PDF Format (Revista Iberoamericana del ATP File RB-01H, 2001), pp. 5-6

7. L. Dube, Users Guide to MODELS in ATP (1996), pp. 74-96

8. M. Dmitriev, G. Evdokunin, and V. Gamilko, IEEE Russia Power Tech (2005)

9. V. Gavrikov, V. Gamilko, and G. Evdokunin, Energetika, 27 (1984)

10. A.S. Brilinskiy, G.A. Evdokunin, and A.D. Petrova, IOP CONF 643 (2019)

11. A. Khakpour, S. Franke, S. Gortschakow, D. Uhrlandt, R. Methling, K-D. Weltmann, IEEE Trans. Power Del 31, 1335 (2016)

12. K. Pedro, Electric Arc Modeling in Circuit Breakers for Electromagnetic Transients Analysis (Instituto Superior T'ecnico, Lisbon, 2017), pp. 4-5

13. T. Ohtaka and R. P. P. Smeets, IEEE Trans. Power Del 33, 1835 (2017)

14. M. M. Walter and C. M. Franck, IEEE Trans. Power Del 29, 580 (2014)

15. J. Martinez, J. Mahseredjian, and B. Khodabakhchian, IEEE Trans. Power Del 20, 2079 (2005)

16. S. Nitu, C. Nitu, C. Mihalache, P. Anghelita, and D. Pavelescu, J OPTOELECTRON ADV M 10, 1192 (2008)

17. H. A. Darwish and N. I. Elkalashy, IEEE Trans. Power Del 20, 772 (2005)

18. Y. Eshaf, M. Matsuoka, M. Kuramochi, Y. Tanguchi, and S. Arai, T.IEE 122-B, 40 (2002)

19. A. Sawicki, PRZ ELEKTROTECHNICZN, ISSN 0033-2097, 270 (2013)

20. G. A. Evdokunin and S. S. Titenkov, Internal Overvoltage in 6-35 kV Networks (Tertsia, St.Petersburg, 2004)

21. K. L. Kadomskaya, A. A. Tihonov, O. V. Tsyrikova, and V. A. Kursish, Energetika, 3 (1994)
22. Ch. M. Dzshuvarly, Electrichestvo, 18 (1953)

23. A. S. Brilinskiy, G. A. Evdokunin, V. S. Chudny, R. I. Mingazov, and T. A. Ponomarev, ElConRus 2018 Proc, 591 (2018)

24. G. A. Evdokunin, S. V. Gudilin, and A. A. Korepanov, He Jishu/Nuclear Techniques 21, 8 (1998)

25. M. V. Dmitriev and G. A. Evdokunin, Izvestiya Akademii Nauk. Energetika 2, 108 (2004)

26. G. A. Evdokunin and S. S. Titenkov, Izvestiya Akademii Nauk. Energetika 1, 91 (2002)

27. A. N. Belyaev, K. A. Izotova, and I. V. Kashin, ElConRus 2018 Proc, 572 (2018) 